\title{
Clinicopathological pattern and risk factors of carcinoma breast in younger age group
}

\author{
Sadia Sharmin, Sarwar Alam, Md. Zillur Rahman Bhuiyan, Md. Nazir Uddin Mollah and Md. Mamun-Or-Rasheed
}

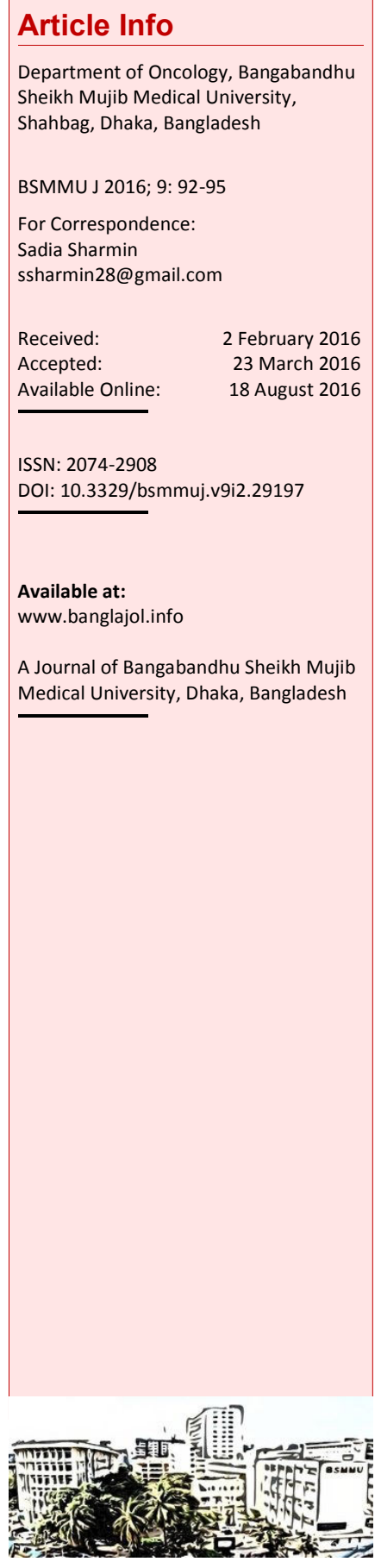

\section{Article Info} Sheikh Mujib Medical University,

BSMMU J 2016; 9: 92-95

For Correspondence:

Sadia Sharmin

Received:

Accepted:

Available Online:

ISSN: 2074-2908

DOI: $10.3329 /$ bsmmuj.v9i2.29197

Available at:

A Journal of Bangabandhu Sheikh Mujib Medical University, Dhaka, Bangladesh

\section{Abstract}

About $7 \%$ of all breast cancers are diagnosed in women $<40$ years of age. Young age at diagnosis influences the prognosis negatively as they present with more advanced disease at diagnosis and a poorer 5-year survival than older patients. The present study includes breast cancer patients in the age group of 18 to 40 years to enrich our knowledge about clinical presentation and pathological characteristics of breast cancer. This cross-sectional study was done on 100 cases of histopathologically proved breast cancer. Structured questionnaire was used as data collection tool. Mean age was 33.9 years. Among the respondents $88 \%$ are married. Among the total studied population, 61 respondents had the history of oral contraceptive pill use. Family history of cancer presents in $13 \%$ respondents. Among the respondents, $95 \%$ patients presented with lump in the breast. $97.0 \%$ had invasive carcinoma $90 \%$ were invasive ductal carcinoma in which $46 \%$ were moderately differentiated. $51.0 \%$ patients were in the stage IIa and stage IIlb.

\section{Introduction}

Breast cancer is the most frequently diagnosed life -threatening cancer and the leading cause of cancer death among women. Increased public awareness and improved screening have led to earlier diagnosis at stages amenable to complete surgical resection and curative therapies. Consequently, survival rates for breast cancer have improved significantly, particularly in younger women. In developed countries, approximately one of four patients are confronted with this diagnosis before the age of 50 years, in other words, at an age when average remaining life expectancy encompasses several decades.1

An ongoing challenge is to find improved methods of identifying and classifying groups of tumours with differing biological behaviours or responsiveness to specific therapies.2 Breast cancer diagnosed at a young age has been correlated with inferior survival and higher recurrence rates when compared with older counterparts. 3

Approximately $7 \%$ of all breast cancers are diagnosed in women $<40$ years of age and less than $4 \%$ in women below the age of 35 . Young age at diagnosis influences prognosis negatively. This could partly be explained by young women more often being diagnosed at advanced stages and by unfavourable tumour characteristics more often being present. Moreover, a review of the National Cancer Data Base revealed that patients younger than 35 years had more advanced disease at diagnosis and a poorer 5-year survival than older patients. Similar findings have been reported in the past from the US National Cancer Institute SEER database, the Finnish Cancer Registry and other sources.

The present study include patients in the age group of 18 to 40 years in different hospitals of Dhaka city to enrich our knowledge about clinical presentation and pathological characteristics of breast cancer.

\section{Materials and Methods}

This cross-sectional study was done over 100 cases of histopathologically proven breast cancer from April 2010 to March 2011 at the Department of Oncology, Bangabandhu Sheikh Mujib Medical University, Department of Radiotherapy of Dhaka Medical Collage \& Hospital and National Institute of Cancer Research and Hospital. Systematic sampling method was applied for the collection of sample. Structured questionnaire was used as data collection tool which contains all the variables of interest of the study such as age, sex, educational level, monthly income status, clinical presentation, histopathological diagnosis of the cancer, treatment status, duration of diagnosis and prognosis of cancer.

\section{Results}

Out of 100 patients, $44 \%$ of patient was in $35-40$ age group. $26 \%$ was in $25-29$ year age group and 
$6 \%$ were 20-24 year age group (Table I). Among the respondents $88 \%$ are married. Among the respondents $72 \%$ were house wife. Monthly family income of the $45 \%$ was in the range of $10,001-20,000$. The habit of betal leaf and nut were $27 \%$ and tobacco chewing $30 \%$. Among the 100 respondents $61 \%$ had the history of oral contraceptive pill use. Family history of cancer presents in 13\% respondents and absent in $87 \%$ respondents. Features of lump on examination were skin thickening, discrete lump, hard, rubbery and tender $28,89,87,4$ and $20 \%$ respectively. Out of 100 respondents, $97 \%$ had invasive carcinoma and only $3 \%$ had non-invasive carcinoma. Among the invasive carcinoma 90 were invasive ductal carcinoma. In grading out of 100 respondents $46 \%$ were moderately differentiated. More than half $(51 \%)$ were in the stage IIa and stage IIb. Progesterone receptor (PR), estrogen receptor (ER) and HER-2 were found in 75, 77 and 37\% patients respectively.

\section{Discussion}

Breast cancer is a common but very diverse disease with considerable survival heterogeneity. An ongoing challenge is to find improved methods of identifying and classifying groups of tumours with differing biological behaviours or responsiveness to specific

\begin{tabular}{|c|c|c|}
\hline \multicolumn{3}{|c|}{ Table I } \\
\hline \multicolumn{3}{|c|}{ Parameter of patients } \\
\hline & & $\mathrm{n}$ \\
\hline \multicolumn{3}{|l|}{ Age (Year) } \\
\hline & $20-24$ & 6 \\
\hline & $25-29$ & 26 \\
\hline & $30-34$ & 24 \\
\hline \multicolumn{3}{|l|}{ Type of carcinoma } \\
\hline & Invasive ductal carcinoma & 90 \\
\hline & Lobular carcinoma & 2 \\
\hline & Medullary carcinoma & 3 \\
\hline & Phyllodes tumor & 2 \\
\hline & Ductal carcinoma & 3 \\
\hline \multicolumn{3}{|l|}{ Staging of tumor } \\
\hline & Stage I & 6 \\
\hline & Stage IIa & 27 \\
\hline & Stage IIb & 24 \\
\hline & Stage IIIa & 20 \\
\hline & Stage IIIb & 18 \\
\hline & Stage IV & 5 \\
\hline \multicolumn{3}{|l|}{ Receptors } \\
\hline \multirow{2}{*}{$\begin{array}{l}\text { Progesterone receptor } \\
\text { (PR) }\end{array}$} & Present & 75 \\
\hline & Absent & 25 \\
\hline \multirow{2}{*}{$\begin{array}{l}\text { Estrogen receptor } \\
\text { (ER) }\end{array}$} & Present & 77 \\
\hline & Absent & 23 \\
\hline \multirow[t]{2}{*}{ HER-2 } & Present & 37 \\
\hline & Absent & 63 \\
\hline
\end{tabular}

therapies.2 Breast cancer diagnosed at a young age has been correlated with inferior survival and higher recurrence rates when compared with older counterparts. 3 Worldwide, breast cancer comprises $22.9 \%$ of all cancers (excluding non-melanoma skin cancers) in women. In 2008, breast cancer caused 458,503 deaths worldwide ( $13.7 \%$ of cancer deaths in women). 4

In the present study, the mean age $( \pm S D)$ of the respondent was $33.9 \pm 4.9$ years with a range of $22-40$ years. Highest number of the respondents were in the age group of above 35 years (44\%). Al though breast cancer is uncommon in young women it is the most frequent cancer in women $<40$ years accounting for 30 $40 \%$ of all female cancer.

Most common occupation of the respondents was housewife $(72 \%)$. Monthly family income of the $45 \%$ cases was in the range of Tk. 10,001-20,000 and 38\% was in the range of Tk. 5,000-10,000. Mean \pm SD = $14,130 \pm 7,397.3$ BDT with a range of 4,000-40,000 BDT. Though breast cancer was most common in the higher socioeconomic condition, in the present study $45 \%$ respondents were in middle class family and it is not similar to population of western countries. Because most of the population in our country within the middle class group. In the present study very few study population belong to higher socioeconomic class. Because most of them receive treatment in the private hospital in home or abroad.

In the present study, it is found that long time $(>10$ years) use of oral contraceptive pill may accelerate the risk of breast cancer. Grabrick et al 5 study had shown that use of oral contraceptives for more than four years prior to first pregnancy increases the risk of breast cancer. In Van Hoften et alo study had shown that long term exposure of ( $>15$ years) OCP increase the risk of breast cancer which is very similar to present study. In the present study the family history of cancer presents in $13 \%$ respondents. The increased risk of breast cancer as a function of family history is well established. Garber et al? study has shown that women with second degree relative with breast cancer, the risk is about 1.5 and for women with a history in first degree relative, the risk is 1.7 to about 1.5 and for women with a history in first degree relative, the risk is 1.7 to 2.5 . The results of present study is not similar to that study. One cause of dissimilarity is that, this study is done among 100 population which is not adequate to draw any conclusion in this relation. Another cause is that there is no available facility for genetic testing.

All respondents were presented with lump in the breast (95\%) among them $89 \%$ were discrete. Olivotto et als found that delays in diagnosis of 6 to 12 month led to an increased risk of larger tumor size and more lymph node metastasis compared with patients diagnosed within 4 to 12 weeks of an abnormal screening mammogram result. In our country most of the people are not well educated and non conscious about breast cancer. So, most of them do not undergo 
any screening program. They also do not do any self breast examination. Most of the cases present with a palpable lump and usually present with locally advance breast cancer. Features of lump on examination were skin thickening, discrete lump, hard, rubbery and tender $28,89,87,4$ and $20 \%$ respectively.

Out of 100 respondents $97 \%$ had invasive carcinoma and only $3 \%$ had non invasive carcinoma. Among the invasive carcinoma 90 were invasive ductal carcinoma, 2 were lobular carcinoma, 3 were medullary carcinoma and rest 2 were phyllodes tumor. Invasive ductal carcinoma is the most common type of breast cancer. Zafrani et al found that $50 \%$ of cases having invasive ductal carcinoma. 9 The present study is similar to that study. Medullary carcinomas are more frequently seen in younger women and are commonly associated with BRCA 1 mutation. In the present study the next common malignancy is medullary carcinoma. But their relation with BRCA 1 could not be excluded.

In grading out of 100 respondents $10.0 \%$ were well differentiated, $46.0 \%$ were moderately differentiated and $44.0 \%$ were poorly differentiated carcinoma. Multiple tumor grading system have been proposed. But Scarff-Bloom-Richardson classification system is utilized mostly. In this system the grading is done according to mitotic index, differentiation and pleomorphism. Score 3 to 5 refer to well differentiated, 6 to 7 refer to moderately differentiated and 8 to 9 refer to poorly differentiated. Joslyn et al10 study found that younger American women usually suffer from high grade breast cancer and have a poorer overall survival. In the present study, $46 \%$ respondents have moderately differentiated and $44 \%$ have poorly differentiated cancer which is similar to that study.

More than half $(51.0 \%)$ were in the stage Ila and stage $\mathrm{IIb}$. Other stages were stage I, stage IIIa and stage IIIb, stage IV were $6.0,20,18$ and $5.0 \%$ respectively. The progressive increase in breast cancer incidence rates observed in Marin County over the past decade is occurring in women with high prevalence of risk factors predisposing toward excess development of $\mathrm{ER}+/ \mathrm{PR}+$ breast cancer11. Progesterone receptor (PR), estrogen receptor (ER) and HER-2 were found in 75, 77 and 37\% respectively. Relative to ductal breast cancers, lobular breast cancers are more commonly ER+.12 ER+ breast cancers are known to account for the progressive increase in United States breast cancer incidence rates after age 45 years with the higher risk subgroup of ER+/PR- breast cancers showing the greatest proportional increase in incidence rates in aging United States populations. In a study, a total of 234 Marin County residents diagnosed as having primary breast cancer were analyzed and found 208 had ER-positive tumors and 26 had ER-negative tumors.13 The frequency of ER-positive breast cancer in women aged 50 years or younger increased 0.0001 .

\section{Ethical Issue}

Written and signed informed consent from the patient was taken for publishing this case report.

\section{References}

1. Brenner $\mathrm{H}$, Hakulinen T. Are patients diagnosed with breast cancer before age 50 years ever cured? J Clin Oncol. 2004; 22: 432-38.

2. Fulford LG, Reis-Filho JS, Ryder K, Jones C, Gillett CE, Hanby A, Easton D, Lakhani SR. Basal-like grade III invasive ductal carcinoma of the breast: Patterns of metastasis and long-term survival. Breast Cancer Res. 2007; 9: R4.

3. Anders CK, Hsu DS, Broadwater G, Acharya CR, Foekens JA, Zhang $Y$, et al. Young age at diagnosis correlates with worse prognosis and defines a subset of breast cancers with shared patterns of gene expression. J Clin Oncol. 2008; 26: 3324-30.

4. World Cancer Report. International Agency for Research on Cancer. 2008. Retrieved 2011-02-26.

5. Grabrick DM, Hartmann IC, Cerhan JR, et. al. Risk of breast cancer with oral contraceptive use in women with a family history of breast cancer. JAMA. 2000; 284: 1791-98.

6. Van Hoften $\mathrm{C}$, et. al. Long-term oral contraceptive use increases breast cancer risk in women over 55 years of age: The Dom Cohort. Int J Can. 2000: 87: 591-94.

7. Garber J, et. al. Sensitivity of genetic testing of BRCA1/BRCA2, and prevalence of other breast cancer susceptibility genes. J Clin Oncol. 2002; 20: 2701-12.

8. Hislop TG, Olivotto IA, Coldman AJ, et al. Variations in breast conservation surgery for women with axillary node negative breast cancer in British Columbia. Can J Public Health. 1996; 87: 390-94.

9. Zafrani B, Aubriot MH, Mouret E, De Cremoux, et al. High sensitivity and specificity of immunohistochemistry for the detection of hormone receptors in breast carcinoma: Comparison with biochemical determination in a prospective study of 793 cases. Histopathology 2000; 37: 536-45.

10. Joslyn SA, West MM. Racial differences in breast carcinoma survival. Cancer 2000; 88: 114-23.

11. Benz CC, Clarke CA, Moore DH II. Geographic excess of estrogen receptor-positive breast cancer. Cancer Epidemiol Biomarkers Prev. 2003; 12: 152327.

12. Stierer M, Rosen H, Weber R, Hanak H, Spona J, Tuchler H. Immunohistochemical and biochemical measurement of estrogen and progesterone 
receptors in primary breast cancer: Correlation of histopathology and prognostic factors. Ann Surg. 1993; 218: 13-21.
13. Hwang ES, Chew T, Shiboski S, Farren G, Benz CC, Wrensch M. Risk factors for estrogen receptor -positive breast cancer. Arch Surg. 2005; 140: 5862. 